\title{
A LA MEMORIA DE LINDA SCHELE (1942-1998)
}

\section{Maricela Ayala Falcón}

Centro de Estudios Mayas, Instituto de Investigaciones Filológicas Universidad Nacional Autónoma de México

Conocí a Linda en 1974, durante el Congreso de Americanistas que se llevó a cabo ese año en México; ella tenía poco tiempo de dedicarse al estudio de los mayas. Llegó junto con Peter Mathews y ambos, instigados por David Kelley, vinieron a exponer ante los americanistas la primera propuesta histórica sobre la dinastía de Palenque. En el congreso estuvo presente Eric Thompson y como la corriente acerca del contenido histórico de los textos jeroglíficos mayas en monumentos aún no era considerada factible, o viable (a pesar de los argumentos históricos), sus planteamientos no fueron bien recibidos por Thompson quien, cabe señalar, tardó varios años en aceptar los cambios en el desciframiento de la escritura maya.

En mi posición de Secretaria Académica del Centro de Estudios Mayas, y aprovechando el Congreso de Americanistas, organicé una reunión a la cual invité a los estudiosos de las escrituras americanas que asistieron a dicho Congreso. Entre ellos estaba David Kelley, quien llegó con Linda y Peter. También estuvieron Joaquín Galarza, quien empezaba a tratar de leer los códices del Altiplano, y Victoria de la Jara, que en ese entonces estaba trabajando, en compañía de Thomas Barthel, sobre la escritura peruana. Todo esto ocurrió en agosto de 1974.

Linda y Peter eran dos jóvenes con aspecto de hippies, un poco taciturnos y mirada de desconfianza. Jamás me hubiera imaginado en ese momento lo que su amistad iba a significar en mi vida.

Estudios de Cultura Maya. Vol. XXII, 2002

Instituto de Investigaciones Filológicas/

Centro de Estudios Mayas, UNAM

ISSN 0185-2574
Todos los que hayan leído el libro de Linda y $\mathrm{Da}$ vid Freidel, A Forest of Kings, sabrán del cómo y por qué Linda y David Schele (su esposo), al equivocar el camino durante sus vacaciones (1970) en México, llegaron a Palenque, y cómo ella en esas vacaciones abandonó su carrera de maestra de arte en la Universidad de Alabama para convertirse en estudiosa de la cultura maya.

Con el apoyo de Merle Greene y Robert Rands se interesó en la iconografía (Primera Mesa Redonda de Palenque), y después en la escritura jeroglífica maya, motivo por el cual estableció contacto con Floyd Lounsbury quien se convirtió en su mentor, como también lo fue David Kelley.

En diciembre de 1973 Merle organizó la Primera Mesa Redonda de Palenque en la cual participó Linda con su trabajo titulado "Observations on the Cross Motifs at Palenque", y fue así como empezó a establecer contacto con varios de los asistentes, mismos con quienes mantendría una estrecha relación a lo largo de su carrera.

En marzo de 1973 Elizabeth Benson promovió una reunión de epigrafistas en Dumbarton Oaks a la cual asistieron, entre otros: Joyce Marcus, Michel Coe, Floyd Lounsbury, David Kelley, Linda Schele y Peter Mathews. Cuando el grupo principal se ausentó para ir a comer (entre otros los mismos E. Benson, M. Coe y J. Marcus) los mayistas restantes, a instancias de Floyd Lounsbury, se pusieron a juntar los datos que tenían sobre Palenque, y cuando el resto del 
grupo regresó ellos ya tenían armada la que sería la base de la dinastía palencana, tema que trajeron a México para presentar en el Congreso de Americanistas, ante el Centro de Estudios Mayas y, ante el crítico más duro: Heinrich Berlin. Ese fue mi primer contacto con Linda, pero hubo muchos más a lo largo de nuestras vidas.

Para diciembre de 1974 se llevó a cabo la Segunda Mesa Redonda de Palenque y a ella asistieron, entre otros, Alberto Ruz, arqueólogo reputado por sus trabajos en la costa de Campeche y descubridor de la tumba de Palenque. Las personalidades de ambos, Linda y Ruz, eran muy diferentes. De hecho Ruz entró en profunda controversia con Linda entre otras cosas por "la edad" del gobernante enterrado bajo la pirámide del llamado Templo de Las Inscripciones, registrada en el borde del sarcófago y obtenida sobre la base de la nueva epigrafía y que entraba en controversia con la edad proporcionada por la antropología física. Otro punto que entró en discusión fue el hecho de que Linda hablaba en sus lecturas de verbos. Verbos cuya presencia, cabe señalar, habían sido identificados por Knorozov (1963, 1965) y por Proskouriakoff (1960, 1963-1964), tres de estos trabajos habían sido publicados en Estudios de Cultura Maya, vols. III, IV y V.

Linda ingresó a la Universidad de Texas, en Austin, para llevar a cabo sus estudios de doctorado y el tema de su disertación fue: The Verb, misma que fue publicada posteriormente por University of Texas Press, y que contiene todos los verbos que aparecían en las inscripciones conocidas hasta ese momento.

Su ingreso a la Universidad de Texas, en Austin, se debió al hecho de que en marzo de 1976 se llevó a cabo el primer Workshop on Maya Hieroglyphs, en el cual Linda presentó, casi sin querer y sin darse cuenta, el inicio de su mayor logro en el campo de la historia: no sólo empezó a recuperar la historia que dejaron escrita los gobernantes mayas, sino que también empezó a difundirla en el ámbito mundial. Y ese fue, posiblemente, el reto que más satisfacciones le produjo, pues de 30 o 40 asistentes al primer Workshop llegaron a participar mas de 500 en el último.

Estudios de Cultura Maya. Vol. XXII, 2002

Instituto de Investigaciones Filológicas/

Centro de Estudios Mayas, UNAM

ISSN 0185-2574
Pero hubo otros retos. En 1985, a raíz de una exhibición de obras mayas en Dallas Fortworth, Tx., publicó con Mary Miller un libro para la exposición titulado The Blood of Kings, mismo que cambiaría no solamente las guías de exposiciones, sino también la imagen de los mayas. Y los mayas cambiaron su personalidad.

De aquella gente pacífica, respetuosa del "dejar hacer, dejar vivir", que no sabía de guerras, conflictos, ni sangre, empezaron a convertirse en gente con un pasado normal, igual al de los otros grupos mesoamericanos que sabían de esas cosas, especialmente de sacrificios. Y la información procedente de las inscripciones mayas cambió la idea que se tenía acerca de los sacrificios, y éstos perdieron el sentido negativo que se les atribuía, fue cuando comenzó a entenderse la relación, tan estrecha, que a través de ellos guardaban dioses y hombres.

En México el libro tuvo un gran impacto cuando Octavio Paz atrajo la atención sobre él. Y los que se sintieron ofendidos por las opiniones de $\mathrm{Paz}$ optaron por negar el avance logrado en el desciframiento de la escritura maya.

Ya entonces los Workshops habían alcanzado tal renombre y difusión que el desciframiento de la escritura no podía continuar siendo negado. Era tapar el Sol con un dedo, y de entre los participantes a los Workshops; norteamericanos, europeos y centroamericanos, muchos se integraron como alumnos del posgrado de la Universidad de Texas para formarse como epigrafistas. Y esa fue la mayor labor de Linda: su capacidad de reunir tanta gente a su alrededor con la cual siempre compartía sus conocimientos, su experiencia y su vida.

Para 1990 publicó, con David Freidel, A Forest of Kings. El primer libro de historia precolombina apoyado en los datos que dejaron escritos los historiadores mesoamericanos. Y nuevamente el libro tuvo tal impacto que fue invitada a México para presentar, junto con otros investigadores, sus ideas y los avances logrados por los epigrafistas.

Con esfuerzo Linda hizo su presentación en español, por respeto al idioma que se habla en México, 
motivo por el cual fue profundamente criticada (1994). No se criticó lo que dijo porque no había argumentos en contra, se criticó "como lo dijo" y se tomó como una ofensa al español. A ella no le preocupó demasiado tal crítica y no faltó quien se aprovechara de sus ideas, las tradujera y usara en su propio provecho.

A su regreso a Austin escribe, con la que suscribe, un artículo para la revista Vuelta que titulamos: "De poesía e historia". Se trata de la lectura del Tablero de los 96 jeroglíficos de Palenque. Este fue su primer artículo publicado en México y con él intentaba devolver a los mexicanos parte de su historia.

En 1995, nuevamente con David Freidel y ahora con Joy Parker, publican Maya Cosmos, que se constituye en un intento por comprender, $y$ comprehender, el Otro mundo maya, el del alma.

A los Workshops se agregaron los Talleres y, posteriormente, los Seminarios, pequeños congresos a los que se invitaba a especialistas en el tema sobre el cual iba a versar el Workshop. La asistencia era cada vez mayor, y el trabajo se incrementaba.

Ya no solamente era investigadora y maestra, también era la receptora de los avances en el desciframiento, y su difusionista a través de las clases, libros, artículos y conferencias. No sólo recibía la información de todo el mundo, también la compartía, y gracias a ella la divulgación del desciframiento se expandió, y aunque muchas de las lecturas e interpretaciones sean criticadas, no hay duda de que si se sigue avanzando, fue gracias a ella.

Durante años las únicas amigas de Linda, en México, fuimos Martha Foncerrada, Beatriz de la Fuente y la que suscribe. En mi caso tuve la suerte y la dicha de haber sido también su alumna. Pero no fui la única latinoamericana a quien invitó y apoyó para llevar a cabo sus estudios en Austin, también apoyó a indígenas mayas de la misma forma, primero en Guatemala y después en México.

A los de Guatemala les enseñó epigrafía, los llevó a Austin para asistir a los Workshops, los albergó en su casa, o en las de sus alumnos, y los ayudó en

Estudios de Cultura Maya. Vol. XXII, 2002

Instituto de Investigaciones Filológicas/

Centro de Estudios Mayas, UNAM

ISSN 0185-2574 todo lo que pudo. Así como abrigó a los indígenas durante los Workshops, muchos de nosotros, cuando no teníamos posibilidades económicas, o en ocasiones por el gusto de tenernos ahí, fuimos instalados en su casa, y debo aclarar que a mí siempre me tocó cama.

Al terminar el Workshop de 1995 Linda tuvo que salir "volando" a la NASA, para "auxiliar" a los científicos y explicarle a los causantes de Estados Unidos por qué tenían que seguir apoyando dicho proyecto de investigación. Tan los convenció que la reunión se tituló; The Administrator Seminar Series. To Boldly Go: The Universe and Beyond.

¿Por qué menciono esto? Porque Linda, como muchos de los de nuestra generación, producto de la postguerra, creemos en un mundo que va hacia delante pero con sus raíces en el pasado. Y seguramente por eso Linda inició su conferencia en NASA explicando que "nuestra labor es como la de los paleontólogos, pero nosotros buscamos los restos del pasado en los libros".

Cuando terminé mis estudios de doctorado en Austin (1994), fuimos a cenar y, además de hablar de Star Trek, platicamos de nuestros planes al futuro, fue entonces cuando me comentó su idea de crear, en el futuro, una Chair en la Universidad de Austin para que los estudios y reuniones sobre epigrafía maya se continuaran realizando en esa universidad. En septiembre de 1997 los médicos le detectaron un cáncer terminal. Cuando supe de su enfermedad hablé con ella y nuevamente, con ese desprendimiento que la caracterizó, me dijo que lo único que pedía era un año, o dos si se podía, para sacar adelante a sus alumnos. Tuvo menos tiempo, pero en cierta forma lo logró pues en el último seminario previo al Workshop sus alumnos participaron en forma importante. Acaban de publicarse sus dos últimos libros; The Code of Kings, con Peter Mathews como coautor (1998), y Rostros ocultos de los mayas (1997), como única autora, con fotografías de Jorge Pérez de Lara, y publicado en México.

Cuando nos despedimos le pedí saludara a mi 
hijo, que ya está en el Cielo, y me contestó: "Es cierto, voy a estar con Carlos", y como los dos son trekies, le pedí que, antes de que se fueran a recorrer el Universo dejaran una nota para que les recordaran que me esperen cuando yo llegue, lo cual me prometió, pero después le hice la gran pregunta; "Y a quién vas a ver primero: a Gene Rodenbery o a Pakal”. Sí. Ella también se rió, y empezó a pensarlo.
Impartió clases, en su casa, hasta el 16 de abril de 1998. Al día siguiente ingresó al hospital. Falleció el 18 de abril a las tres de la tarde, dentro de la Iglesia Griega Ortodoxa, estando con ella sus amigos, alumnos y, por supuesto su querido esposo David Schele, que fue quien la trajo a México la primera vez, y por quien conoció a los mayas.

Gracias Linda. 